\title{
Feasibility of Micellar Surface Charge Decoration of Graphene Oxide with Surfactants and Oils as Adsorbents for Natural and Synthetic Pigments (A Review)
}

\section{CHINAWOOTH SAKAEW ${ }^{1}$, PRAWIT NUENGMATCHA², PHITCHAN SRICHAROEN ${ }^{1}$, NUNTICHA LIMCHOOWONG ${ }^{1}$ and SAKSIT CHANTHAI ${ }^{1 *}$}

\author{
${ }^{1}$ Materials Chemistry Research Center, Department of Chemistry and Center of Excellence for Innovation \\ in Chemistry, Faculty of Science, Khon Kaen University, Khon Kaen 40002, Thailand. \\ ${ }^{2}$ Nanomaterials Chemistry Research Unit, Department of Chemistry, Faculty of Science and Technology, \\ Nakhon Si Thammarat Rajabhat University, Nakhon Si Thammarat 80280, Thailand. \\ ${ }^{*}$ Corresponding author E-mail: sakcha2@kku.ac.th \\ http://dx.doi.org/10.13005/ojc/340302
}

(Received: January 31, 2018; Accepted: February 18, 2018)

\begin{abstract}
This paper reviews the use of a well-known graphene oxide (GO) as an adsorbent in solid phase extraction (SPE) of plant pigments like $\beta$-carotene and other dye contaminants under optimum conditions. Numerous researches had investigated the influence of some surfactants and oils, in particular typically including sodium dodecyl sulfate (SDS), polyethylene glycol p-(1,1,3,3-tetramethylbutyl)-phenyl ether (TX100) and hexadecyltrimethylammonium bromide (CTAB) as auxiliary agents to link in and then modify the polarity of the surface charge of $\mathrm{GO}$. The applicability of SPE based on SDS-GO, TX100-GO and CTAB-GO in real samples was compiled and discussed. The surfactant/oil-surface charge decoration of the GO sorbents for rapid SPE can thus be a potential and suitable candidate for the selective procedure of dispersive solid-phase microextraction of total carotenoids and/or contaminated synthetic dyes from vegetables, fruits or food products.
\end{abstract}

Keywords: Graphene oxide, Surfactant, Oil, Adsorbent, Natural and Synthetic Pigments.

\section{INTRODUCTION}

Generally, humans have living factors as diets, clothes, havens, and medicines. One of these factors will determine healthy lifestyle, good health, happiness, and no illness. The remark "you are what you eat" is the golden words that guide people to focus on the diets which are very better than ever. Healthy foods such as vegetarian foods and low fatty meals are the proportional arrangement of the five food groups. In fruits and vegetables, their variation of phytochemicals is of importance for the biologically active compounds that found in plants. The interestingly important substance is

This is an Open Access article licensed under a Creative Commons Attribution-Non Commercial-Share Alike 4.0 International License (https://creativecommons.org/licenses/by-nc-sa/4.0/), which permits unrestricted Non Commercial use, distribution and reproduction in any medium, provided the original work is properly cited. 
carotenoids that generally found in some fruits and vegetables such as chili and tomato. In this work, it is to focus on the $\beta$-carotene as the representative of the carotenoids from a variety of samples. A group of the phytochemicals that was mostly found in the color type of fruits and vegetables such as tomato and papaya, even the colorlessness such as potato is also the carotenoids. $\alpha-, \gamma-, \beta$-Carotene, lycopene, lutein, zeaxanthin, and their isomers, which are a proportional assistant role in human cell activities and human growing systems, have been well investigated ${ }^{1}$. The recent studies have described on carotenoids as components of the human antioxidative systems and comprehensive studies to the marker substances for the human antioxidative status ${ }^{2,3}$.

\section{Carotenoids}

In the recent years, the research studies of carotenoids regarding various fields were developed worldwide. The analytical separation of five carotenoids using of reversed-phase high-pressure liquid chromatography (HPLC) was a long time developed ${ }^{4}$. Later years, many spectroscopic techniques were used to detect the carotenoids with high sensitivity, selective, and non-invasive samples ${ }^{5-8}$. Raman active molecules are presented by the light absorption to induce the stretching and/or bending of covalent bonds. As the Raman characterization of carotenoids, the rocking motion of the methyl group as three prominent Stokes lines appears at $1005 \mathrm{~cm}^{-1}, 1156 \mathrm{~cm}^{-1}(C-C$ stretching vibration) and $1523 \mathrm{~cm}^{-1}$ ( $\mathrm{C}=\mathrm{C}$ stretching vibration), these bonds are interesting mark to activate antioxidative property of the carotenoids ${ }^{9,10}$.

The well-known, efficient benefits of carotenoids such as antioxidant, against all risk of the negative cell changing or against aging and natural dyeing have been demonstrated. In the business fields, these advantages are possibly considered in the application on the development of new products. Medicine, dermal carotenoids, cosmetology, green chemical dyeing, dietary science, and other combined applications are widely included in many important parts to research and development of the carotenoids contained products which are almost beneficial for a new approach on a human being.

\section{Graphene oxide}

Materials science is one of the most interesting fields of sciences which is supplemented the various techniques of the analytically scientific research such as adsorption, desorption, pollution, bleaching, purification, preconcentration even if determination based on extraction techniques. The mother of materials is namely of graphene which has many forms following their dimensional assemblies such as graphene quantum dot, single and multi-wall carbon nanotube, tube-in-tube nanostructure, carbon nanofiber, carbon nanorod ${ }^{11}$, carbon nanosheet, graphene film ${ }^{12-14}$, fullerene, and graphene/polymer composite ${ }^{15-17}$. Each form presents the different superior physical and chemical properties those are useful advantaged applications ${ }^{18-20}$.

This work focuses on the graphene oxide sheets because of a simple synthesis that presents the low-cost carbon-based materials. Ensuing, the amazing finding of fullerenes and carbon nanotubes in last times, graphene has newly become an exhilarating new space in the arena of carbon nanoscience and condensed matter physics. Graphene, discovered by Geim et al., at the University of Manchester in 2004 ${ }^{21}$, is a two-dimensional material including layers of carbon atoms arranged in six-membered rings. It can be seen as the foundation of all carbon materials with fullerenes and carbon nanotubes. It can be wrapped to form fullerene, scrolled to form a carbon nanotube and stacked to form graphite (Fig. 1). Graphene was the first created by a micromechanical cleaving technique. The method provided a few high-quality samples for necessary studies. Future, it has similarly been synthesized by the desorption of $\mathrm{Si}$ from $\mathrm{SiC}$ single-crystal surfaces ${ }^{22,23}$; by a chemical vapor deposition (CVD) method with a surface precipitation process of carbon in some transition metals ${ }^{24-29}$; and by a chemical solution method ${ }^{30}$.

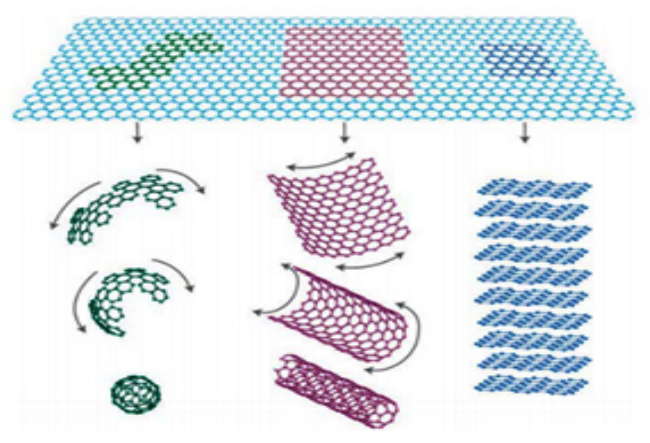

Fig. 1. Graphene and its relation to fullerenes, CNTs, and graphite ${ }^{31}$ 
From Fig. 1, various popular forms of graphene were produced. Fullerene was formed by rolling as a ball formation with bulky space center. When graphene was rolled to be a tube, its carbon nanotube was obtained. Different benefits are thus attributed in various fields depending on their different shapes. Graphene is a monocrystalline graphite film with a few atoms thick and is steady under ambient conditions. Its two-dimensional honeycomb lattice of carbon atom has freshly appeared as an exciting material for electronics due to fast electron transporter movement in bulk graphene, low density and large particular surface area ${ }^{32-34}$. In recent years, it has been increased the sensitivity of metal detection due to its uncommon electronic, thermal, and mechanical properties ${ }^{35-40}$. For research study, it was established the worth of graphene nanosheets in a raising of the high sensitivity sensor for the determination of lead and cadmium ions ${ }^{41,42}$. It was then demonstrated that the interaction and charge transfer between graphene and metal ions that exactly improves a lot of sensitivity of the modified electrode ${ }^{43}$. Earlier works reporting the graphene mixed with a binding agent such as Nafion and then the drop-layered onto a glassy carbon electrode surface have productively been used to detect trace heavy metal ions in water samples ${ }^{44}$. Additionally, the glassy carbon electrode reformed with chemically reduced graphene oxide and without using any binding agent can be adapted for cadmium determination ${ }^{45}$. Thus, it is extremely hopeful for the expansion of new kinds of chemical/biological sensors with ultrahigh sensitivity due to succeeding details: the first, graphene is a two-dimensional material and each atom can be exposed to the surface which gets the most out of the sensing effect. The second, graphene's highly conductive properties and crystal can confirm a low level of noise those are affected by the thermal switching. The third electronic properties of graphene are sensitive to both electron donor and acceptor molecules, which make a high potential for sensing applications $^{46}$.

Since the graphene oxide (GO) discovery, it was the convenient material that was used in the analytical chemistry research. As the famous properties of the sorption, there are widely uses of this material such as inorganic dye bleaching, pollution removal, worth organic purification, and preconcentration ${ }^{47}$. The micro sheet molecule of graphite does the high adsorptive mechanism, but pi-pi stacking is the most excess strong interaction that acting in the desorption step. The chemical synthesized GO from the graphite powder can be impressively solving the problem by their oxide functional groups on the surface. Graphene oxide shows the effective abilities of the sorbent which is highly adsorbed and effectively desorbed in the one type material. Willam S. Hummers and Richard E. Offeman created the most popular chemical method for GO synthesis. Hummer's method can do the various oxide functional groups on the graphene surface. Graphite powder is strongly oxidized by potassium permanganate and sodium nitrate as the co-oxidative agent for peeling of a graphene sheet by the pushing of oxide groups across the sheets, moreover the secondary oxidation is done when the method is modified by adding of hydrogen peroxide, so the epoxy bridges, hydroxyl groups, and carboxyl groups there are on the graphene oxide surface ${ }^{48}$.

For the creative target in analytical chemistry, there was not only GO but also the surface modified GO was strikingly used. Some of the heavy metal ions in water do the pollutant that impact to human and living things. Amount limitation of the toxins is adopted by the United States Environmental Protection Agency (USEPA) and public safe considered by the World Health Organization (WHO). That information was considered for determination of the sorbent performance. The worth of graphene oxide does not stop at the toxic removal, a process in the pharmaceutical industries do the loss of the number of valuable compounds which are carried by wastewater. The synthetic surface modification of GO that has benefit to reuse or recycle the value compound again, moreover the reducing of waste water is also done ${ }^{49}$.

From the foregoing, we focus on the basic sorbent property of graphene oxide because of their facile synthesis, low cost, fast adsorption, and application of simple analysis methods as mentioned above. The previous studies have reported the diversity of their applications, but there are only a few reports in the salutary chemical or phytochemical analysis such as the carotenoids. The phytochemicals have been applied to the healthy trends, green chemistry, medical technology, organic food pigments, and the other future applications. 


\section{Improving adsorbent efficiency}

Ultrasonic assisted adsorption is one of the modern techniques, which is interesting due to their easy process, simple, rapid, cheap, and more effective, not only for the primary analytical techniques but also for the simultaneous purposes ${ }^{50}$. The ability of ultrasonication is the transferring of energies from the sources to all directions of the targets, generating the vibrations associated with the heat. These powers build some analytical techniques such as extraction, desolvation based sonication, gas-degradation, and adsorption-desorption techniques ${ }^{51-53}$. The trend in $\beta$-carotene adsorption on the surface of graphene oxide using ultrasonication is a green approach. Due to the hydrophobic property, $\beta$-carotene will likely be adsorbed on the graphene oxide ${ }^{54}$. Furthermore, it is noticed the possibility of their $\pi-\pi$ interactions between $\beta$-carotene in a normal form and the carbon network of graphene oxide sheets, perhaps which can escalate this adsorption capacity ${ }^{55}$. When this adsorption is available, some techniques are used to develop for improving the adsorption efficiency.

Adsorption is generally a surface spectacle, at which a substance in the bulk phase takes place at the interface or the surface for the process accumulation or concentration that generates the concentration gradient between surface phase and its bulk one. Gas and liquid phases around the solid surface site contain analytical molecules. The miracle of adsorption was first observed for gases declarative to carbon. It gave the reversible removal of color and compounds from water by wood charcoal. The surface accumulation from an intermolecular perforation confirms by the simple character of an adsorption process ${ }^{56}$. The most two types of adsorption are called physisorption and chemisorption. The adsorption is referred to as physical adsorption when the drawing between the solid surface and adsorbed molecules is physical in natural surroundings therein the attractive forces are Van der Waals forces, ensuing in reversible adsorption. Then, chemisorption has the higher force of chemical bonding between the solid surfaces and the adsorbed molecules, creating it hard to eliminate the chemisorbed species from the solid surface. So, the adsorption process has more benefits to the construction of applicable techniques in analytical chemistry.
Moreover, only of the physisorption and chemisorption are not enough for the analytical efficiency applications. The scientific developments of adsorption to generate the chemical and physical forces were born for the analysts such as the improving attraction by using ultrasound assisted adsorption. The development of solid surface interactions and/or complexation by using adsorbent modification is concerned. Sodium dodecyl sulfate (SDS), cetyltrimethylammonium bromide (CTAB) and Tween20 are the choices of use as the surface modifying agent due to its long carbon chain (tail) with a poor polarity which can induce the carbon chain attraction. In the other hand, they have the head polarity which is giving different reactive activity to graphene oxide, so the head group should be interacted to be neutralization of surface charge of graphene oxide. The interactions of $\beta$-carotene on $\pi$-bonding of the rigid structure of graphene oxide and on the hydrophobic tail of the surfactant were determined ${ }^{57,58}$. Thus, the possible micellar surface charge modification of the graphene oxide with facile surfactants was demonstrated and discussed.

\section{Adsorption study of the carotenoids}

Lately, the plant carotenoids were used as a component in commercial products, especially for a human being. The known benefits for their adsorption characteristics are available and compiled in Table 1.

\section{Comparison of the applied method with other reported methods}

From the Table 2, we compiled instrumental techniques for the determination of $\beta$-carotene. Many analytical techniques were used with separating couples such as thin layer chromatography and liquid chromatography for the advantage of their separation, although those techniques need a number of special expert persons to control the instrument ${ }^{68-74}$. Some techniques were coupled with the flow injection for the advantage of the compact automatic online determination system. In this work, we used simple technique like UV-Visible spectrometry for the demonstration of a basic method for development as same as the previous literature ${ }^{70}$. The lowest detection limit was not indicated from this work, but that was seemingly matched in the low-level group. Adsorption study of dyes by graphene oxide 
Table 1: The adsorption characteristics of the carotenoids by different liquid-solid phases

\begin{tabular}{|c|c|c|}
\hline Sample & Adsorption characteristic & Reference \\
\hline $\begin{array}{l}\text { Lycopene, } \beta \text {-carotene, } \\
\text { lutein, canthaxanthin }\end{array}$ & $\begin{array}{l}\text { Liposome composed of mixed liquids including egg yolk } \\
\text { phosphatidylcholine and Tween } 20 \text { as nanocarriers }\end{array}$ & [59] \\
\hline $\begin{array}{l}\beta \text {-apo-8'-carotenoic acid, } \\
\beta \text {-carotene }\end{array}$ & Adsorption at n-hexane phase (oil) to oil/water interface & {$[60]$} \\
\hline$\beta$-carotene & $\begin{array}{l}\text { Adsorption of } \beta \text {-carotene on natural and chemically } \\
\text { modified bentonite }\end{array}$ & {$[61]$} \\
\hline$\beta$-carotene & $\begin{array}{l}\text { Mesoporous carbon coated monolith as an adsorbent for } \\
\text { adsorption of } \beta \text {-carotene from crude palm oil }\end{array}$ & {$[62]$} \\
\hline$\beta$-carotene & Adsorption behavior of $\beta$-carotene on synthetic adsorbent & [63] \\
\hline$\beta$-carotene & $\beta$-Carotene adsorbed on acid-activated sepiolite & [64] \\
\hline$\beta$-carotene, chlorophyll & $\begin{array}{l}\beta \text {-Carotene and chlorophyll adsorption onto acid-activated } \\
\text { bentonite in xylene solution }\end{array}$ & {$[65]$} \\
\hline$\beta$-carotene, phosphorus & $\begin{array}{l}\text { Adsorption of carotenes and phosphorus from palm oil onto } \\
\text { acid activated bleaching earth }\end{array}$ & {$[66]$} \\
\hline$\beta$-carotene & Adsorption of $\beta$-carotene from soy oil with the regenerated clay & {$[67]$} \\
\hline
\end{tabular}

Table 2: Instrumental techniques for the determination of $\beta$-carotene

\begin{tabular}{lll}
\hline Instrumental technique & LOD & Ref. \\
\hline Ultra-high performance supercritical fluid chromatography & $0.95 \mu \mathrm{gg} / \mathrm{mL}$ & {$[68]$} \\
Ultra-high performance supercritical fluid chromatography-mass spectrometry & $0.017 \mu \mathrm{g} / \mathrm{mL}$ & {$[69]$} \\
Thin-layer chromatography-densitometry & $103 \mu \mathrm{g} / \mathrm{mL}$ & {$[70]$} \\
Multicommutated flow injection analysis-fluorescence spectrophotometry & $0.09 \mu \mathrm{g} / \mathrm{mL}$ & {$[71]$} \\
High-performance liquid chromatography-diode array detector & $0.012 \mu \mathrm{g} / \mathrm{mL}$ & {$[72]$} \\
Fluorescence spectrophotometry & $0.003 \mu \mathrm{g} / \mathrm{mL}$ & {$[73]$} \\
Liquid chromatography-diode array-tandem mass spectrometry & $0.06 \mu \mathrm{\mu g} / \mathrm{g}$ & {$[74]$} \\
Ultra-performance convergence chromatography & $0.03 \mu \mathrm{\mu g} / \mathrm{mL}$ & {$[75]$} \\
One step solid-liquid extraction/high-performance liquid chromatography & $0.629 \mu \mathrm{g} / \mathrm{g}$ & {$[76]$} \\
\hline
\end{tabular}

Presently, textiles, leather tanning, plastics, hair coloring and food technology, synthetic dyes have been used to color their finishing products. Chiefly, malachite green (MG) and alizarin red $S$ (ARS) are two kinds of the greatest generally used colors for cotton, leather, silk, paper and printing inks ${ }^{67}$. Especially, MG can also be used as an anti-parasitic and antifungal agent in aquariums ${ }^{75}$. Nevertheless, it and its major metabolite, leucomalachite green, both have mutagenic, carcinogenic, genotoxic and teratogenic effects ${ }^{76,77}$. When environmental pollution happens, they bio-accumulate in aquatic life for example fish, crab, shrimp, mollusk and other animals ${ }^{78,79}$ and reason detrimental effects in liver, gall, kidney, intestine, gonad, and pituitary gonadotrophic cells ${ }^{80}$. Eventually, a human being has been affected by food chain danger becoming sick. Therefore, it is required to remove these dye contaminants from wastewater before a releasing into the environment to keep both the environment and humans.

In recent times, graphene oxide (GO) was established to be a candidate carbon-based adsorbent due to having of non-specific functional groups (carbonyl, hydroxyl, and epoxide) on its surface, providing anchor sites for both dye and metal ion complexation. The great quantity 
of functional groups on its surface provides its adsorption capability for various dye contaminants. A series of $\mathrm{GO}$ with different oxidation degrees for the elimination of methylene blue (MB) from aqueous solution was described ${ }^{81,82}$. The GO series show a total fast adsorption, which is used to capable of removing trace levels of dye entirely from very dilute solution. Additionally, they reported that the binding geography of the MB loaded GO progressively changes from MB molecule parallel stacking on graphite plane via hydrophobic $\pi-\pi$ interaction to vertical standing through electrostatic interaction with increasing oxidation degrees, resulting in an improvement of the MB uptake.

The presentation of graphene oxide for the removal of congo red (CR) dye from aqueous solution was also estimated ${ }^{83}$. Batch sorption studies were carried out to decide the effect of $\mathrm{pH}$, contact time, initial concentration of $\mathrm{CR}$ and temperature on the adsorption of $\mathrm{CR}$ onto GO. Circumneutral $\mathrm{pH}$ was set up to be promising for the adsorption of CR onto the adsorbent. The equilibrium data worked well with the Redlich-Peterson model and characterized by a Langmuir-type isotherm. The kinetic factors are drawn from the kinetic studies advised that the adsorption procedure is the film-diffusion-controlled. The results are also obtained from thermodynamic studies exposed that the adsorption course is endothermic in nature as better as the possibility and spontaneity of CR adsorption.

For the effect of an immobilized GO on such crowd structure, it was incorporated into calcium alginate and macroporous alginic beads, and acridine orange $(A O)$ was used as a typical dye pollutant to remove ${ }^{84}$. Characterizations confirmed that $\mathrm{GO}$ was better encapsulated and had encouraged both beads more porous yet to a varying extent. Kinetics studies showed the addition of GO resulted in adsorption with shorter equilibrium time and quicker initial adsorption rate, and the adsorbents with greater equilibrium capacities. Isotherm lessons designated the hybrid absorbents following Langmuir-type adsorptive activities which had greatly maximum adsorption capacity.

The magnetic hybrid nanomaterials could be organized by calcining graphene oxide (GO)/layered double hydroxide (LDH) hybrid in nitrogen atmosphere ${ }^{85}$. This nanomaterial displays outstanding adsorption ability toward methyl orange (MO) in aqueous solution. In addition, the magnetic hybrid similarly shows worthy reprocess ability for MO removal. This innovative nanomaterial-derived from the hybrid material demonstrates unlimited potential in the applications of water management. In regard to use the exfoliated graphene oxide (EGO) and reduced graphene oxide ( $\mathrm{rGO}$ ) for the adsorption of various charged dyes such as $\mathrm{MB}$, methyl violet, rhodamine $\mathrm{B}$, and orange $\mathrm{G}$ from aqueous solution ${ }^{86}$, the enormous negative charged density available makes assisting the effective adsorption of cationic dyes on EGO while its adsorption is insignificant for the anionic dyes. Alternatively, rGO that has high surface area does not dominate as a high negative charge and is found to be very good adsorbent for the anionic dyes. From these studies, it is noted that there is no report regarding the applications of graphene-based materials for the organic colorants such as the plant pigments. Thus, this proposal is aimed to employ the graphene oxide in association with micellar surface charge modification with surfactants for the extraction of $\beta$-carotene from the carotenoid extracts from aqueous solution and/or oil-water phase by using adsorption technique. Solid-phase extraction (SPE) is the interesting technique for separation of an analytical molecule from a matrix. It started when a selected adsorbent was packed in a container and converted to an appropriate condition. Then the sample was spiked to the system, the analytical molecule would release itself from the matrix to the adsorbent active site. This process depended on the appropriation of chemical and physical property between the analyte and adsorbent. After washing step was done by original-like solvent rinsing in several times, an appropriated eluted solvent was chosen to extract the analyte. The appropriate condition would be done with high recovery after the optimization was proved. In this field, the carbon-based materials such as graphene and graphene derivative were used to be an adsorbent, as shown in Table 3 for several applications.

According to the graphene-based materials for new SPE sorbent in Table 3 many field of analytical molecules was used to do the SPE by pure graphene as an adsorbent such as the fluorescence spectrometry for determination of glutathione in 
human plasma ${ }^{87}$, cooperation with high performance liquid chromatography (HPLC) for separation of chlorophenols in tap water ${ }^{88}$, separation of phthalate acid esters in river water by ultrahigh-performance liquid chromatography ${ }^{90}$, and the analysis of lipophilic marine toxins in shellfish ${ }^{95}$. Furthermore, functionally modified graphene, composite of graphene, and monolithic graphene fibers were used for analysis of polycyclic aromatic hydrocarbons (PAHs) in river water by gas chromatography (GC), $\mathrm{Pb}(\mathrm{II})$ in vegetable juice by flame atomic absorption, rare earth elements in its oxide by microwave plasma torch-atomic emission spectrometry, and PAHs in environmental water by GC, respectively ${ }^{89,91,92,94}$. Rafal Sitko et al., said that graphene has a strong affinity for organic compound, it is considered a serious advantage of graphene in SPE, but the strong $\pi-\pi$ stacking interaction between graphene sorbent and the analyte is the cause of the incomplete elution and the hard extraction by several solvents. In Table 3, oxide of graphene was used to analysis of aflatoxins in peanuts by HPLC, giving the lowest limit of detection (LOD) at $0.08-0.65 \mathrm{ng} / \mathrm{g}^{93}$. For these different properties of graphene oxide and graphene, the oxide groups gave the interested polar function to graphene with the advantages of spreading in water, modification of the polar functional groups, easy removing from container or column, and easy elution with the several solvents. In this work, we selected graphene oxide as the SPE adsorbent for application of the carotenoid extraction. Moreover, the extraction efficiency of graphene oxide and the raw carbon-based material such as activated carbon and graphite was compared for consideration of the advantage of graphene oxide as an adsorbent.

Table 3: Application of carbon-based material in solid-phase extraction

\begin{tabular}{|c|c|c|c|c|c|c|c|}
\hline Analyte & Sample & Adsorbent & Elution & RSD (\%) & $\begin{array}{c}\text { LOD } \\
(\mathrm{ng} / \mathrm{mL})\end{array}$ & Instrument & Ref. \\
\hline Glutathione & Human plasma & Graphene & Methanol & 5.0 & $0.01 \mathrm{nM}$ & $\mathrm{FL}$ & [87] \\
\hline Chlorophenols & Tap water & Graphene & Methanol & $2.2-7.7$ & $0.1-0.4$ & HPLC & [88] \\
\hline $\mathrm{PAHs}$ & River water & $\begin{array}{l}\text { Sulfonated } \\
\text { graphene }\end{array}$ & Toluene & $1.0-9.0$ & $\begin{array}{c}0.8-4.0 \\
\mathrm{ng} / \mathrm{L}\end{array}$ & GC-MS & [89] \\
\hline $\begin{array}{l}\text { Phthalate } \\
\text { acid esters }\end{array}$ & River water & Graphene & Ethyl acetate & e $1.0-10$ & $2-7$ & GC-MS & [90] \\
\hline $\mathrm{Pb}(\mathrm{II})$ & Vegetable juice & $\begin{array}{l}\text { Graphene/ } \\
\text { dithizone }\end{array}$ & $\mathrm{HNO}_{3}$ & 3.5 & 0.61 & FAAS & [91] \\
\hline $\begin{array}{l}\text { Rare earth } \\
\text { elements }\end{array}$ & $\begin{array}{l}\text { Rare earth } \\
\text { elements oxide }\end{array}$ & $\begin{array}{l}\text { Graphene/ } \\
\mathrm{TiO}_{2}\end{array}$ & $\mathrm{HNO}_{3}$ & 1.3-3.6 & 1.6-2.8 & MPT-AES & [92] \\
\hline Aflatoxins & Peanuts & $\begin{array}{l}\text { Graphene } \\
\text { oxide }\end{array}$ & Methanol & $1.7-4.5$ & $\begin{array}{c}0.08-0.65 \\
\mathrm{ng} / \mathrm{g}\end{array}$ & HPLC-FL & [93] \\
\hline $\mathrm{PAHs}$ & $\begin{array}{l}\text { Environment } \\
\text { (water) }\end{array}$ & $\begin{array}{l}\text { Monolithic } \\
\text { graphene fibers }\end{array}$ & $\begin{array}{l}\text { Thermal } \\
\text { desorption }\end{array}$ & 9.4 & $\begin{array}{c}4.0-50 \\
\mathrm{ng} / \mathrm{L}\end{array}$ & $\mathrm{GC}$ & [94] \\
\hline $\begin{array}{l}\text { Lipophilic } \\
\text { marine } \\
\text { toxins }\end{array}$ & Shellfish & $\begin{array}{l}\text { Graphene } \\
\text { (pipette tip) }\end{array}$ & Acetonitrile & $1.01-3.56$ & $1.5 \mu \mathrm{g} / \mathrm{kg}$ & $\begin{array}{l}\text { UPLC- } \\
\text { MS/MS }\end{array}$ & [95] \\
\hline
\end{tabular}

Oil-in-water emulsions and their functionalities

Emulsions and nanoemulsions in the oil-in-water form are generally applied in cosmetics, healthcare, pharmaceutical industries, supplement, and foods. They can release, protect, and encapsulate non-polar compounds ${ }^{96-98}$. These compounds are nutraceuticals, nutrients, vitamins, colors, flavors, drugs, antimicrobials, and antioxidants which may enter the dispersed phase in the emulsion or dissolve in some carrier oils such as flavor, essential, flaxseed, or fish oils. Carotenoids and vitamins are dissolved in corn oil. Composition and microstructure are the key factors those present gastrointestinal fate, sensory attributes, and the physicochemical properties of the oil-in-water emulsions ${ }^{99}$. So, the different functional emulsions can be carefully invented by adjusting 
their composition and microstructure. The selection of specific components (such as surfactants, co-surfactants, solvent, co-solvent, and oil), and specific homogenization conditions (such as homogenizer types and operating conditions) will be rendered the emulsion ${ }^{100-104}$. The functional presentations of oil-in-water emulsions are powerfully reliant on the nature of the oil droplets (Fig. 2) $)^{106-109}$. An outline of the relationship between droplet properties and emulsion performance is specified, this information is beneficial for understanding the goal of utilizing post-homogenization methods to modify emulsion functionalities, as shown in Table 4.

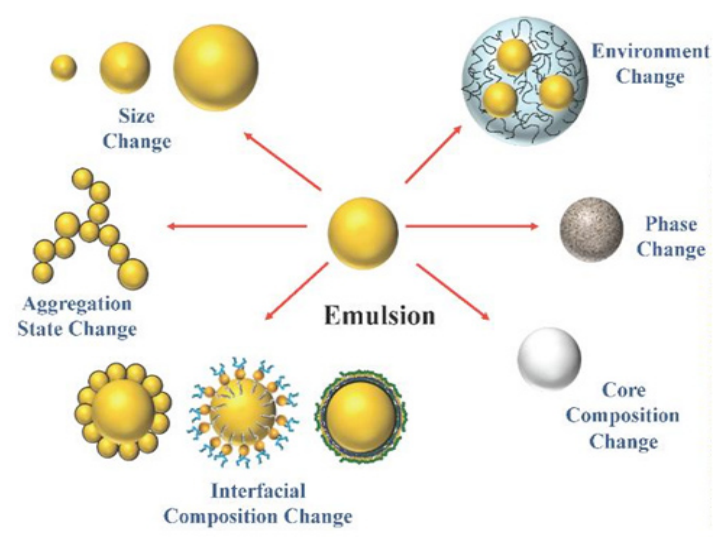

Fig. 2. The droplets in an oil-in-water emulsion may be changed ${ }^{105}$

The droplets formed against environmental stresses are not chiefly effective stabilized by a few sorts of emulsifiers, but small droplets during homogenization are extremely effective produced. Equally, environmental stresses are resisted by the droplets which are greatly effective produced by other types of emulsifiers, but minor droplets during homogenization are not mainly produced. So, in some situations, it may keep improving to operate one type of emulsifier to form an emulsion containing minor droplets, and then to change the interfacial properties subsequently. In addition, it may be necessary to modify the interfacial properties of an emulsifier after homogenization to alter its properties, e.g., to generate droplets with different electrical characteristics. Instance, the magnitude of the droplet charge is strongly depended by the physical stability of emulsions in commercial yields, and how it vagaries with $\mathrm{pH}$ and ion addition, since this effects the attractive and repulsive colloidal interactions operating between the droplets ${ }^{63}$. The chemical permanency of emulsions droplet charge is similarly depended by themselves. It has been notified that the emulsified unsaturated lipids can be oxidized more rapidly when the droplets are negatively charged because the positively charged transition metals that catalyze the oxidation to their surfaces is much more attracted.

Hence, it may be needed to alter the electrical appearances of the emulsion droplets after they have been formed. Modifications in interfacial composition and properties after homogenization can be accomplished using a number of approaches, those are presented. The surfactant exchange approach has been used to develop the permanence of emulsions formed using low energy methods, such as the phase inversion temperature or spontaneous emulsification approaches ${ }^{128,129}$. In some cases, the formation of an emulsion is often simplified using a non-ionic surfactant, the spontaneous generation of small oil droplets is simplified when the systematic composition or temperature is changed. On the other hand, these surfactants frequently lead to the construction of emulsions that are extremely unstable to coalescence, particularly at raised temperatures. The stability of the emulsions can be developed after formation by displacing the original surfactant from the droplet surfaces using another surfactant. This method was used to increase the thermal stability of phase inversion temperature (PIT) nanoemulsions ${ }^{128}$. The nanoemulsions were designed from hydrocarbon oil (tetradecane), a non-ionic surfactant (Brij 30), and water using the phase inversion temperature technique. A mixture of the surfactant, oil, and water was quickly cooled from above to below the PIT to naturally form a nanoemulsion. Nevertheless, these nanoemulsions were greatly prone to droplet coalescence when the temperature was quite close to the PIT. The thermal constancy of these emulsions was enhanced by adding another non-ionic surfactant (Tween 20) or an anionic surfactant (SDS) after their formation to upsurge the PIT or to raise the repulsive colloidal interactions. A similar methodology has been used to stabilize nanoemulsions formed using the spontaneous emulsification process ${ }^{129}$. Surfactant conversation has also been used to 
adjust the electrical charge on emulsion droplets after homogenization ${ }^{130}$. Emulsions containing oil droplets with a squat net charge were prepared by homogenizing oil and water together in the habitation of a non-ionic surfactant (Tween 80), and then the charge was changed by adding either cationic (lauric arginate) or anionic (SDS) surfactants to the system. A range of droplet charges from extremely positive to extremely negative could be generated using this approach.

For an interfacial deposition, these methods contain depositing a substance onto the surfaces using some attractive force. Usually, the force is an electrostatic one between a charged substance and an oppositely charged droplet, but other forces could similarly be used, such as hydrophobic force or hydrogen bond formation ${ }^{99,131,132}$. The substances that are deposited onto the surface of an emulsion droplet may be biopolymers (proteins or polysaccharides) or colloidal particles (silica, titanium dioxide, or chitin nanoparticles). By far the most frequently used interfacial deposition method has been layer-by-layer electrostatic deposition of charged biopolymers onto oppositely charged oil droplets ${ }^{132}$. Classically, a primary emulsion is completed using an electrically charged emulsifier (anionic surfactant or protein), and then the emulsion is mixed with a solution enclosing oppositely charged biopolymer molecules. Under appropriate conditions, this indicates the formation of oil droplets covered by a surfactant-biopolymer layer (Fig. 3). This progression can be repeated a number of times using a series of biopolymer solutions with alternating charge characteristics. One must be cautious to the device the biopolymer and droplet concentrations during this process to dodge depletion or bridging flocculation within the emulsion ${ }^{131,133}$. The electrostatic deposition method has also been used to generate a layer of charged small oil droplets nearby the oppositely charged great oil droplets ${ }^{134-136}$. The novel inspiration of the preconcentration is a modification of the material surface.

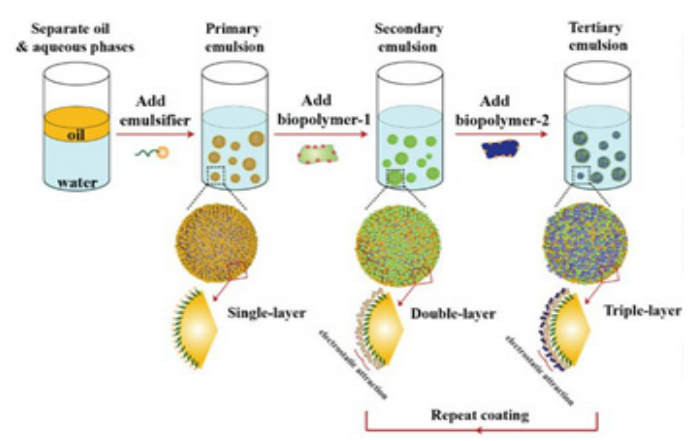

Fig. 3. The interfacial composition of the droplets in an oil-in-water emulsion may be altered after homogenization by electrostatic deposition method $^{105}$.

Table 4: Impact of droplet properties on an emulsion functionality

Impact of droplet property Emulsion functionality

Droplet concentration

- An increasing of the oil droplet concentration makes the viscosity of an oil-in-water emulsion increase because of the greater energy dissipation associated with friction ${ }^{106}$.

- Due to close packing (jamming) of the oil droplets simultaneously, the high droplet concentrations and emulsion achieve some solid-like characters $^{110}$.

- Greater light scattering does the increase of the lightness of an emulsion as the droplet concentration increases ${ }^{108}$.

- When the movement of the droplets have proved, the stability of an emulsion to creaming or sedimentation tends to improve after the droplet concentration increases ${ }^{109,111,112}$.

- The increasing of droplet concentration since the frequency and duration of droplet-droplet encounters increase may decrease the stability of an emulsion to flocculation and coalescence ${ }^{113}$.

- Essentialities of many emulsion-based foods are the increasing of 
Droplet size

Droplet charge and

Disperse phase composition

Physical state

Physical state oil droplet concentration when the awareness of creaminess of an emulsion tends to increase ${ }^{107,114}$.

- Light scattering efficiency of the droplets depends on their size interrelated to the wavelength of the light is mostly used to determine the optical properties of emulsions ${ }^{108}$.

- While the rate of Ostwald ripening is increasing, the speed of droplet flocculation, coalescence, and gravitation separation tended to decrease with the decreasing of droplet size ${ }^{113,115-117}$.

- When the thickness of the interfacial layer is on a well-matched length scale as the dimensions of the oily core, the droplet size may also have an effect on the rheological properties of emulsions by alteration of their effective volume ${ }^{108,109}$.

- Due to the decreasing of the diffusion pathway, the release rate of encapsulated substances within emulsion droplets may increase as the droplet size decrease ${ }^{118}$.

- The thin layer of emulsifier molecules, which was coated the oil influence on its functional attributes. So, the chosen of suitable emulsifiers and solution conditions such as $\mathrm{pH}$, ionic strength, and temperature can also control the charge, thickness, packing, and chemical reactivity of the other interfacial properties interfacial layer ${ }^{119}$.

- The strength of the steric repulsion increases as the increasing of the thickness of the interfacial layer while the strength of the electrostatic repulsion between oil droplets is tending to increase as their electrical potential increases. That demonstrates the interfacial properties which have the main influence on the physical stability of emulsions ${ }^{115}$.

- The dependence on the rate of Ostwald ripening on the interfacial tension and rheology has been proving ${ }^{120}$.

- The releasing of encapsulated substances that sound nice same as the impaction of interfacial properties on the chemical stability of the oil phase ${ }^{118,121}$.

- Oils with different densities, interfacial tensions, viscosities, solvent properties, nutritional attributes, and polarities can be applied depending on the application. The ability to generate emulsions that remain steady after homogenization, as well as many of these oil phase characteristics influence the ability to procedure small droplets in emulsions during homogenization ${ }^{96}$.

- Lipid oxidation, speed, and extent of digestion are accepted as one of the chemical stability of emulsion and two of the disperse phase composition's gastrointestinal fate, respectively, which may be solved by the disperse phase composition ${ }^{122,123}$.

- Since oil-in-water emulsion is essential that both the oil and water phases be in a fluid state through the homogenization process, the droplets within are regularly liquid. However, it is possible for the oil phase to crystallize and form solid particles under exact conditions. A number of ways have shown for the functional performance of the droplets may be influenced by the physical state of the oil droplets ${ }^{124}$.

- Since an oil-in-water emulsion is essential that both the oil and water phases be in a fluid state through the homogenization process, the droplets within are regularly liquid. However, it is possible for the oil phase to crystallize and form solid particles under exact conditions. A number of ways have shown for the functional 
Local environment

Droplet spatial distribution performance of the droplets may be influenced by the physical state of the oil droplets ${ }^{124}$.

- The first way is the density of the oil droplets normally increased which will adjust the softness of creaming and sedimentation ${ }^{96}$.

- The second way is the refractive index of the oil droplets typically increased which will increase the degree of light scattering ${ }^{125}$.

- The third way is the speed of molecular diffusion inside the oil phase. It will tend to be reduced when the lipid phase turns out to be solid, which may be beneficial for inhibiting of unwanted chemical reactions or inhibiting release of the encapsulated bioactive molecules ${ }^{118,126}$.

- The functional attributes of the oil droplets may be modified by the native environment of themselves inside emulsion. While the aqueous phase close to the oil droplets may vary in its ingredient or structure, the chemical stability of any components trapped within the oil can be changed by the event ${ }^{127}$.

- An emulsion containing flocculated droplets behaves vary otherwise from one containing isolated droplets. For instance, a flocculated emulsion has a tendency to have a greatly higher viscosity than a non-flocculated emulsion at the same oil content. Apart from that, the droplets in a dilute emulsion are apt to cream further quickly when they are flocculated since the increase in particle size. Nevertheless, the droplets in a concentrated emulsion may cream more gradually when they are flocculated because a three-dimensional particle network is formed that estricts droplet movement ${ }^{111}$.

\section{CONCLUSION}

In the recent years, researchers have finished their works with the doping of heteroatom to materials by that heteroatom contained reagents adding. So, this review focuses various types of surfactants for a demonstration that strategies, such as sodium dodecyl sulfate (SDS) for anionic modification, polyethylene glycol $p$-(1,1,3,3-tetramethyl butyl)phenyl ether (Triton $\mathrm{X}$-100) for the non-ionic modification and hexadecyltrimethylammonium bromide (CTAB) for cationic modification. In this regards, we look forward to create the adsorption method for an extraction of the carotenoids by using the adsorption property of graphene oxide as the green adsorbent. The synthetic sorbent is synthesized by the modified Hummers' method.
The extraction process is modified by using some desired surfactants, the interesting surfactants are such as SDS, Triton X-100, and CTAB, for the anionic, non-ionic, and cationic surfactant, respectively, for example. The proposed method would certainly enhance the limit of detection of the target analytes with good accuracy and precision.

\section{ACKNOWLEDGEMENT}

This review article was financially supported by Materials Chemistry Research Center, and Department of Chemistry and Center of Excellence for Innovation in Chemistry (PERCH-CIC), Faculty of Science, Khon Kaen University, Khon Kaen, Thailand.

\section{REFERENCES}

1. Darvin, M.E.; Sterry, W.; Lademann, J.; Vergou, T. Molecules, 2011, 16, 10491-10506.

2. Haag, S.F.; Taskoparan, B.; Darvin, M.E.; Groth, N.; Lademann, J.; Sterry, W.; Meinke,
M.C. Experim. Dermato., 2011, 20, 183-487.

3. Lademann, J.; Meinke, M.C.; Sterry, W.; Darvin, M.E. Experim. Dermato., 2011, 20, 377-382. 
4. Talwar, D.; KK Ha, T.; Cooney, J.; Brownlee, C.; St JO'Reilly, D. Clinica Chimica Acta., 1998, 270, 85-100.

5. Ermakov, I.V.; Ermakova, M.R.; Gellermann, W.; Lademann, J. J. Biomed. Optics., 2004, 9, 332-338.

6. Darvin, M.E.; Gersonde, I.; Meinke, M.; Sterry, W.; Lademann, J. J. Phys. D: Applied Phys., 2005, 38, 2696-2700.

7. Lademann, J.; Caspers, P.J.; van der Pol, A.; Richter, H.; Patzelt, A.; Zastrow, L.; Darvin, M.; Sterry, W.; Fluhr, J.W. Laser Phys. Lett., 2009, 6, 76-79.

8. Stahl, W.; Heinrich, U.; Jungmann, H.; von Laar, J.; Schietzel, M.; Sies, H.; Tronnier, H. J. Nutr., 1998, 128, 903-907.

9. Stahl, W.; Sies, H. Molecular Nutr. Food Res., 2011, 56, 287-295.

10. Krinsky, N.I.; Johnson, E.J. Molecular Aspec. Med., 2005, 26, 459-516.

11. Zhu, Z.; Su, D.; Weinberg, G.; Schlögl, R. Nano Lett., 2004, 4, 2255-2259.

12. Dikin, D.A.; Stankovich, S.; Zimney, E.J.; Piner, R.D.; Dommett, G.H.B.; Evmenenko, G.; Nguyen, S.T.; Ruoff, R.S. Nature Lett., 2007, 448, 457-560.

13. Tang, L.; Wang, Y.; Li, Y.; Feng, H.; Lu, J.; Li, J. Adv. Funct. Mat., 2009, 19, 2782-2789.

14. Wu, Q.; Xu, Y.; Yao, Z.; Liu, A.; Shi, G. ACS Nano., 2010, 4, 1963-1970.

15. Cote, L.J.; Cruz-Silva, R.; Huang, J. J. Amer. Chem. Soc., 2009, 131, 11027-11032.

16. Vickery, J.L.; Patil, A.J.; Mann, S. Adv. Mat., 2009, 21, 2180-2184.

17. Cai, D.; Song, M. J. Mat. Chem., 2010, 20, 7906-7915.

18. Novoselov, K.S.; Fal'ko, V.I.; Colombo, L.; Gellert, P.R.; Schwab, M.G.; Kim, K. Nature., 2012, 490, 192-200.

19. Huang, X.; Qi, X.; Boey, F.; Zhang, H. Chem. Soc. Rev., 2012, 41, 666-686.

20. Chua, C.K.; Pumera, M. Chem. Soc. Rev., 2014, 43, 291-312.

21. Novoselov, K.S.; Geim, A.K.; Morozov, S.V.; Jiang, D.; Zhang, Y.; Dubonos, S.V.; Grigorieva, I.V.; Firsov, A.A. Science, 2004, 306, 666-669.

22. Berger, C.; Song, Z.; Li, X.; Wu, X.; Brown, N.; Naud, C.; Mayou, D.; Li, T.; Hass, J.; Marchenkov, A.N.; Conrad, E.H.; First, P.N.; de Heer, W.A. Science, 2006, 312, 1191-1196.
23. Emtsev, K.V.; Bostwick, A.; Horn, K.; Jobst, J.; Kellogg, G.L.; Ley, L.; McChesney, J.L.; Ohta, T.; Reshanov, S.A.; Röhrl, J.; Rotenberg, E.; Schmid, A.K.; Waldmann, D.; Weber, H.B.; Seyller, T. Nature Mat., 2009, 8, 203-207.

24. Sutter, P.W.; Flege, J.I.; Sutter, E.A. Nature Mat., 2008, 7, 406-411.

25. Yu, Q.; Lian, J.; Siriponglert, S.; Li, H.; Chen, Y.P.; Pei, S.S. Applied Phys. Lett., 2008, 93, 113103.

26. Kim, K.S.; Zhao, Y.; Jang, H.; Lee, S.Y.; Kim, J.M.; Kim, K.S.; Ahn, J.H.; Kim, P.; Choi, J.Y.; Hong, B.H. Nature Lett., 2009, 457, 706-710.

27. Reina, A.; Jia, X.; Ho, J.; Nezich, D.; Son, H.; Bulovic, V.; Dresselhaus, M.S.; Kong, J. Nano Lett., 2009, 9, 30-35.

28. Coraux, J.; N'Diaye, A.T.; Busse, C.; Michely, T. Nano Lett., 2008, 8, 565-570.

29. Li, U.; Cai, W.; An, J.; Kim, S.; Nah, J.; Yang, D.; Piner, R.; Velamakanni, A.; Jung, I.; Tutuc, E.; Banerjee, S.K.; Colombo, L.; Ruoff, R.S. Science, 2009, 324, 1312-1314.

30. Park, S.; Ruof, R. Nature Nanotechnol., 2009, 4, 217-224.

31. Geim, A., K.; Novoselov, K.S. Nature Mat., 2007, 6, 183-191.

32. Zbeda, S.; Pokpas, K.; Titinchi, S.; Jahed, N.; Baker, G.P.; Iwuoha, E.I. Inter. J. Electrochem. Sci., 2013, 8, 11125-11141.

33. Wang, X., Tabakman, S.M. and Dai, H. J. American Chem. Soc., 2008, 130, 8152-8153.

34. Yang, H.; Li, F.; Shan, C.; Han, D.; Zhang, Q.; Niu, L.; Ivaska, A. J. Mat. Chem., 2009, 19, 4632-4638.

35. Novoselov, K.S.; Geim, A.K.; Morozov, S.V.; Jiang, D.; Katsnelson, M.I.; Grigorieva, I.V.; Dubonos, S.V.; Firsov, A.A. Nature Lett., 2005, 438, 197-200.

36. Tombros, N.; Jozsa, C.; Popinciuc, M.; Jonkman, H.T.; van Wees, B.J. Nature Lett., 2007, 448, 571-574.

37. Wu, Z.-S.; Ren, W.; Wen, L.; Gao, L.; Zhao, J.; Chen, Z.; Zhou, G.; Li, F.; Cheng, H.-M. ACS Nano, 2010, 4, 3187-3194.

38. Balandin, A.A.; Ghosh, S.; Bao, W.; Calizo, I.; Teweldebrhan, D.; Miao, F.; Lau, N. Nano Lett., 2008, 8, 902-907.

39. Dikin, D.A.; Stankovich, S.; Zimney, E.J.; Piner, R.D.; Dommett, G.H.B.; Evmenenko, G.; Nguyen, S.T.; Ruoff, R.S. Nature Lett., 2007, 448, 457-460. 
40. Stankovich, S.; Dikin, D.A.; Dommett, G.H.B.; Kohlhaas, K.M.; Zimney, E.J.; Stach, E.A.; Piner, R.D.; Nguyen, S.T.; Ruoff, R. Nature Lett., 2006, 442, 282-286.

41. Li, J.; Guo, S.; Zhai, Y.; Wang, E. Anal. Chim. Acta., 2009, 649, 196-201.

42. Li, J.; Guo, S.; Zhai, Y.; Wang, E. Electrochem. Commun., 2009, 11, 1085-1088.

43. Khomyakov, P.A.; Giovannetti, G.; Rusu, P.C.; Brocks, G.; van den Brink, J.; Kelly, P. J. Phys. Rev. B, 2009, 79, 195425-195437.

44. Willemse, C.M.; Tlhomelang, K.; Jahed, N.; Baker, P.G.; Iwuoha, E.I. Sensors., 2011, 11, 3970-3987.

45. Wong, C.H.A.; Pumera, M. RSC Adv., 2012, 2, 6068-6072.

46. Novoselov, K.S.; Jiang, D.; Schedin, F.; Booth, T.J.; Khotkevich, V.V.; Morozov, S.V.; Geim, A.K. Proc. Nat. Acad. Sci. USA., 2005, 102, 10451-10453.

47. Jiao, L.M.; Yu, Y.X.; An, Z.C.; Jia, Y.; Hao, H.; Bao, W.X. Chinese Sci. Bull., 2013, 58, 26982710.

48. Konkena, B.; Vasudevan, S. J. Phys. Chem. let., 2012, 3, 867-872.

49. Sitko, R.; Zawisza, B.; Malicka, E. Trends in Anal. Chem., 2013, 51, 33-43.

50. Gürkan, R.; Korkmaz, S.; Altunay, N. Talanta, 2016, 155, 38-46.

51. Khezeli, T.; Daneshfar, A.; Sahraei, R. Talanta, 2016, 150, 577-585.

52. Zhao, X.-E.; Lv, T.; Zhu, S.; Qu, F.; Chen, G.; He, Y.; Wei, N.; Li, G.; Xia, L.; Sun, Z.; Zhang, S.; You, J.; Liu, S.; Liu, Z.; Sun, J.; Liu, S. J. Chromatogr. A., 2016, 1437, 49-57.

53. Tan, T.; Lai, C.-J.-S.; Yang, H.O.; He, M.-Z.; Feng, Y. J. Pharma. Biomed. Anal., 2016, 120, 134-141.

54. van den Berg, H.; van Vliet, T. American J. Clinical Nutr., 1998, 68, 82-89.

55. Sies, H.; Stahl, W. American J. Clinical Nutr., 1995, 62, 13155-13215.

56. Sanghi, R.; Verma, P. Coloration Technol., 2012, 129, 85-108.

57. Rehfeld, S.J. J. Phys. Chem., 1967, 71, 738-745.

58. Wanless, E.J.; Ducker, W.A J. Phys. Chem., 1996, 100, 3207-3214.

59. Tan, C.; Feng, B.; Zhang, X.; Xia, W.; Xia, S. Food Hydrocoll., 2016, 52, 774-784.

60. Joos, P.; Tomoaia-Cotisel, A.; Sellers, A.J.;
Tomoaia-Cotisel, M. Colloids and Surfaces B: Biointerf., 2004, 37, 83-91.

61. Gonzalez-Pradas, E.; Villafranca-Sanchez, M.; Valverde-Garcia, A. Mat. Chem. Phys., 1991, 27, 307-319.

62. Muhammad, Choong, T.S.Y.; Chuah, T.G.; Yunus, R.; Taufiq Yap, Y.H. Chem. Engineer. J., 2010, 164, 178-182.

63. Ahmad, A.L.; Chan, C.Y.; AbdShukor, S.R.; Mashitah, M.D. Chem. Engineer. J., 2009, 148, 378-384.

64. Sabah, E.; Çinar, M.; Çelik, M., S. Food Chem., 2007, 100, 1661-1668.

65. Wu, Z.; Li, C. J. Hazardous Mat., 2009, 171, 582-587.

66. Silva, S.M.; Sampaio, K.A.; Ceriani, R.; Verhé, R.; Stevens, C.; Greyt, W.D.; Meirelles, A.J.A. J. Food Engineer., 2013, 118, 341-349.

67. Ma, M.-H.; Lin, C.-I. Sep. Purif. Tech., 2004, 39, 201-209.

68. Mysliwa-Kurdziel, B.; Jemioła-Rzeminska, M.; Turek, E.; Strzałka, K.; Malec, P. Acta Biochimica Polonica., 2012, 59, 57-60.

69. Jin, H.; Lao, Y.M.; Zhou, J.; Zhang, H.J.; Cai, Z.H. J. Chromatogr. A, 2017, 1488, 93-103.

70. Alarcón, F; Báez, M.E.; Bravo, M.; Richter, P.; Fuentes, E. Talanta, 2012, 100, 439-446.

71. Caballo, C.; Costi, E.M.; Sicilia, M.D.; Rubio, S. Food Chem., 2012, 134, 1244-1249.

72. Yuan, F.; Qian, M.C. Food Chem., 2016, 192, 633-641.

73. Annunziata, M.G.; Attico, A.; Woodrow, P.; Oliva, M.A.; Fuggi, A.; Carillo, P. J. Food Comp. Anal., 2012, 27, 145-150.

74. Divya, P.; Puthusseri, B.; Neelwarme, B. Food Res. Inter., 2012, 45, 342-350.

75. Pasquet, V.; Chérouvrier, J.-R.; Farhat, F. Thiéry, V.; Piot, J.-M.; Bérard, J.-B.; Kaas, R.; Serive, B.; Patrice, T.; Cadoret, J.-P.; Picot, L. Process Biochem., 2011, 46, 59-67.

76. Solovchenko, A.E.; Avertcheva, O.V.; Merzlyak, M.N. Postharvest Biol. Tech., 2006, 40, 183-189.

77. Akar, E.; Altinisik, A.; Seki, Y. Eco. Engineer., 2013, 52, 19-27.

78. Podstawczyk, D.; Witek-Krowiak, A.; Chojnacka, K.; Sadowski, Z. Bioresource Technol., 2014, 160, 161-165.

79. Arellano-Cárdenas, S.; López-Cortez, S.; Cornejo-Mazón, M.; Mares-Gutiérrez, J.C. Applied Surf. Sci., 2013, 280, 74-78. 
80. Srivastava, S.; Sinha, R.; Roy, D. Aquatic Toxicol., 2004, 66, 319-329.

81. Fallah, A.A.; Barani, A. Food Control., 2014, 40, 100-105.

82. Sudova, E.; Machova, J.; Svobodova, Z.; Vesely, T. Veterinarni Medicina., 2007, 52, 527-539.

83. Kalpana, P.; King, P. Asian J. Chem., 2014, 26, 75-81.

84. Yan, H.; Tao, X.; Yang, Z.; Li, K.; Yang, H.; Li, A.; Cheng, R. J. Hazard. Mat., 2014, 268, 191-198.

85. Debnath, S.; Maity, A.; Pillay, K. J. Environ. Chem. Engineer., 2014, 2, 260-272.

86. Sun, L.; Fugetsu, B. Chem. Engineer. J., 2014, 240, 565-573.

87. Yang, Z.; Ji, S.; Gao, W.; Zhang, C.; Ren, L.; Tjiu, W.W.; Zhang, Z.; Pan, J.; Liu, T. J. Coll. Interf. Sci., 2013, 408, 25-32.

88. Ramesha, G.K.; Vijaya Kumara, A.; Muralidhara, H.B.; Sampath, S. J. Coll. Interf. Sci., 2011, 361, 270-277.

89. Huang, K.-J.; Jing, Q.-S.; Wei, C.-Y.; Wu, Y.-Y. Spectrochim. Acta Part A: Mol. Biomol. Spectr., 2011, 79, 1860-1865.

90. Liu, Q.; Shi, J.; Zeng, L.;Wang, T.; Cai, Y.; Jiang, G. J. Chromatogr. A, 2011, 1218, 197-204.

91. Zhang, H.; Low, W.P.; Lee, K. J. Chromatogr. A, 2012, 1233, 16-21.

92. Wu, X.; Hong, H.; Liu, X.; Guan, W.; Meng, L.;Ye, Y.; Ma, Y. Sci. Total Envir., 2013, 444, 224-230.

93. Wang, Y.; Gao, S.; Zang, X.; Li, J.; Ma, J. Anal. Chim. Acta., 2012, 716, 112-118.

94. Zhang, J.; Cheng, R.; Tong, S.; Gu, X.; Quan, X.; Liu, Y.; Jia, Q.; Jia, J. Talanta, 2011, 86, 114-120.

95. Yu, L.; Li, P.; Zhang, Qi.; Zhang, W.; Ding, X.; Wang, X. J. Chromatogr. A, 2013, 1318, 27-34.

96. Fan, J.; Dong, Z.; Qi, M.; Fu, R.; Qu, L. J. Chromatogr. A., 2013, 1320, 27-32.

97. Shen, Q.; Gong, L.; Baibado, J.T.; Dong, W.; Wang, Y.; Dai, Z.; Cheung, H.-Y. Talanta, 2013, 116, 770-775.

98. McClements, D. J. Adv. Colloid Interf. Sci., 2012, 174, 1-30.

99. Silva, H.D.; Cerqueira, M.A.; Vicente, A.A. Food Bioprocess Tech., 2012, 5, 854-867.

100. Velikov, K.P.; Pelan, E. Soft Matter, 2008, 4, 1964-1980.

101. McClements, D. J. Curr. Opin. Colloid Interf. Sci., 2012, 17, 235-245.

102. Maindarkar, S.N.; Hoogland, H.; Henson,
M.A Colloids and Surfaces A: Physicochem. Engineer. Aspects., 2015, 467, 18-30.

103. Raikar, N.B.; Bhatia, S.R.; Malone, M.F.; Henson, M.A. Chem. Engineer. Sci., 2009, 64, 2433-2447.

104. Hakansson, A.; Innings, F.; Tragardh, C.; Bergenstahl, B. Chem. Engineer. Sci., 2013, 91, 44-53.

105. Galooyak, S.S; Dabir, B.; Zolfaghari, M. Colloids and Surfaces A: Physicochem. Engineer. Aspects., 2015, 487, 169-179.

106. Bai, L.; McClements, D.J. J. Colloid Interf. Sci., 2016, 466, 206-212.

107. Bai, L.; McClements, D., J. Processes., 2016, 4, 17.

108. Derkach, S.R. Adv. Colloid Interf. Sci., 2009, 151, 1-23.

109. Le Reverend, B. J. D.; Norton, I.T.; Cox, P. W.; Spyropoulos, F. Curr. Opin. Colloid Interf. Sci., 2010, 15, 84-89.

110. McClements, D. J. Adv. Colloid Interf. Sci., 2002, 97, 63-89.

111. Robins, M.M. Curr. Opin. Colloid Interf. Sci., 2000, 5, 265-272.

112. Pal, R. Food Hydrocolloids., 2006, 20, 997-1005.

113. Chanamai, R.; McClements, D.J. Colloids and surfaces A: Physicochem. Engineer. Aspects, 2000, 172, 79-86.

114. Sek, J.; Jozwiak, B. J. Dispersion Sci. Tech., 2015, 36, 991-999.

115. Rahn-Chique, K.; Urbina-Villalba, G. Asociación Interciencia., 2015, 40, 847-853.

116. Van Aken, G.A.; Vingerhoeds, M.H.; de Wijk, R.A. Food Hydrocolloids., 2011, 25, 789-796.

117. McClements, D. J. Soft Matter., 2011, 7, 2297-2316.

118. McClements, D.J.; Rao, J. Critical Rev. Food Sci. Nutr., 2011, 51, 285-330.

119. Taylor, P. Adv. Colloid Interf. Sci., 1998, 75, 107-163.

120. Dan, N. J. Food Engineer., 2016, 175, 136-144.

121. Salcedo-Sandoval, L.; Cofrades, S.; RuizCapillas, C.; Matalanis, A.; McClements, D.J.; Decker, E.A.; Jimenez-Colmenero, F. Food Chem., 2015, 184, 207-213.

122. Mun, S.H.; McClements, D. J. Langmuir., 2006, 22, 1551-1554.

123. Berton-Carabin, C.C.; Ropers, M.H.; Genot, C. Comprehensive Rev. Food Sci. Food Safety., 2014, 13, 945-977. 
124. Boon, C.S.; Xu, Z.; Yue, X.; McClements, D.J.; Weiss, J.; Decker, E.A. J. Agric. Food Chem., 2008, 56, 1408-1414.

125. Qian, C.; Decker, E.A.; Xiao, H.; McClements, D. J. Food Chem., 2012, 135, 1440-1447.

126. Santana, R.C.; Perrechil, F.A.; Cunha, R.L. Food Engineer. Rev., 2013, 5, 107-122.

127. Helgason, T.; Salminen, H.; Kristbergsson, K.; McClements, D.J.; Weiss, J. J. Colloid Interf. Sci., 2015, 448, 114-122.

128. Jenning, V.; Schafer-Korting, M.; Gohla, S. J. Controlled Release, 2000, 66, 115-126.

129. Mei, L.Y.; McClements, D.J.; Decker, E.A. J. Agric. Food Chem., 1999, 47, 2267-2273.

130. Rao, J.J.; McClements, D. J. J. Agric. Food
Chem., 2010, 58, 7059-7066.

131. Saberi, A.H.; Fang, Y.; McClements, D. J. J. Agric. Food Chem., 2014, 62, 1625-1633.

132. Ziani, K.; Chang, Y.H.; McLandsborough, L.; McClements, D.J. J. Agric. Food Chem., 2011, 59, 6247-6255.

133. Guzey, D.; McClements, D. J. Adv. Coll. Interf. Sci., 2006, 128, 227-248.

134. McClements, D. J. J. Food Sci., 2010, 75, R30-R42.

135. Zeeb, B.; Thongkaew, C.; Weiss, J. J. Applied Poly. Sci., 2014, 131.

136. Gu, Y.S.; Decker, E.A.; McClements, D. J. Food Hydrocolloids., 2007, 21, 516-526. 